\title{
Effect of Parathyroid Function After Thyroidectomy and Radioactive-Iodine Therapy for Thyroid Disease
}

\author{
Liu Xiao, Wenjie Zhang and Lin Li* \\ Department of Nuclear Medicine, China
}

*Corresponding author: Lin Li, Department of Nuclear Medicine, West China Hospital of Sichuan University, No. 37. Guoxue Alley, 610041 Chengdu, Sichuan province, PR. China

\begin{abstract}
ARTICLE INFO
Received: 幽 November 01, 2019

Published: 幽 November 08, 2019

Citation: Liu Xiao, Wenjie Zhang, Lin Li. Effect of Parathyroid Function After Thyroidectomy and Radioactive-Iodine Therapy for Thyroid Disease. Biomed J Sci \& Tech Res 22(4)-2019. BJSTR. MS.ID.003780.
\end{abstract}

Keywords: Thyroidectomy; Radioactive-Iodine; Hyperthyroidism; Differentiated Thyroid Carcinoma; Parathyroid Gland Function

Abbreviations: TMNG: Toxic Multinodular Goiter; DTC: Differentiated Thyroid Cancer; RAI: Radioactive Iodine; PTH: Parathyroid Hormone; ICG: Indocyanine Green

\section{ABSTRACT}

Objective: Thyroidectomy and radioactive-iodine (RAI) treatment are two important methods for benign and malignant thyroid diseases. Thyroidectomy and RAI treatment may influence parathyroid gland function. This paper systematically reviewed the literatures on the effect of thyroidectomy and RAI on parathyroid gland function in patients with benign and maligant thyroid disease.

Subjective and Methods: We searched PubMed for English literautres by using terms of "thyroidectomy" or "radioactive iodine" and "hyperthyroidism" or "Graves' disease" or "toxic multinodular goiter" or "toxic adenoma" or "differentiated thyroid carcinoma" and "parathyroid gland" or "calcium" or "parathyroid hormone" to review the effect of thyroidectomy and RAI on parathyroid gland function.

Result: Thyroidectomy may lead to hypocalcaemia and hypoparathyroidism both for benign thyroid disease and DTC. For benign thyroid disease, RAI treatment may cause increasing PTH in the short term and may induce parathyroid adenoma or hyperplasia in the long term. For DTC patients, parathyroid gland function may transiently decline after RAI treatment.

Conclusion: Thyroidectomy and RAI treatment may influence the parathyroid function in both benign and DTC patients. Thus, it is important to monitor PTH and blood calcium regularly in order to detect early abnormal parathyroid function for those patients.

\section{Introduction}

The thyroid gland is the largest endocrine gland in the human body. It secretes thyroid hormones that affect the metabolism. Hyperthyroidism including Graves' disease (GD), toxic multinodular goiter (TMNG), toxic adenoma (TA) and differentiated thyroid cancer (DTC) are common thyroid diseases, for which thyroidectomy and radioactive iodine (RAI) treatment can be used. The parathyroid gland is an endocrine organ, which consists of 4 small glands located posteriorly to the thyroid in the middle aspect of the anterior neck and secretes parathyroid hormone (PTH), a polypeptide in response to low calcium levels detected in the blood. Low calcium can lead to circumoral or peripheral paranesthesia, tetany, carpopedal spasm, laryngospasm, and ECG changes from long QT interval to VT arrest [1,2]. While high calcium can cause fatigue, polyuria, polydipsia, nephrolithiasis, peptic ulcer disease, altered mental status, gait instability [3-5], myalgia, arthralgia, abdominal pain [4], rare submandibular gland atrophy and sialolithiasis, metastatic pulmonary calcification [6,7], sometimes even inducing acute kidney injury or acute pancreatitis [8-13], or being life-threatening $[14,15]$.

The parathyroid gland is an adjacent organ of the thyroid. Theoretically, thyroidectomy and RAI may influence parathyroid function. The impairment of parathyroid glands and the thyroid function can produce some corresponding symptoms. It is necessary to focus on the effect of RAI and thyroidectomy treatment on parathyroid function. We searched PubMed for English language studies by using terms of "surgery" or "thyroidectomy" or "radioactive iodine" and "hyperthyroidism" or "Graves' disease" or "toxic multinodular goiter" or "toxic adenoma" or "differentiated thyroid 
carcinoma" and "parathyroid gland" or "calcium" or "parathyroid hormone (PTH)" to summarize the effect of thyroidectomy and RAI on parathyroid gland function in patients with above mentioned benign and malignant thyroid diseases.

\section{Effect of Thyroidectomy on Parathyroid Function}

Thyroidectomy meaning partial or complete removal of thyroid tissue is among the most frequently performed surgical procedures in general surgery for thyroid disease including differentiated thyroid carcinoma (DTC) and hyperthyroidism. Postoperative hypocalcemia due to hypoparathyroidism is the most common complication of thyroidectomy, with a reported incidence of 1.6\% - 50\% [16-18]. It is reported that post-operative hypocalcemia is frequently occurred in the first and second post-operative days. Permanent hypoparathyroidism after total thyroidectomy is associated with an increased risk of death [19]. Hypocalcemia after thyroidectomy for benign diseases, apart from more frequent symptoms of hypocalcemia in patients with Graves' disease, there were no differences in the overall frequency of biochemical hypocalcemia or decreasing PTH among benign and malignant thyroid diseases [20,21]. Generally thyroidectomy for hyperthyroidism rendered a patient to an euthyroid state faster than RAI [22]. After surgery for hyperthyroidism, young age, operative time, type of hospital, and parathyroid auto-transplantation were associated with early postoperative hypocalcemia [23].

Incidental parathyroidectomy with a reported incidence of $6.4 \%-31.1 \%$, was thought to be associated with postoperative hypocalcemia. Central neck dissection, total thyroidectomy, larger thyroid dimensions, extrathyroidal extension, tumor diameter more than $10 \mathrm{~mm}$, autoimmune thyroid disease, substernal goiter, females' gender were found to be significant risk factors of incidental parathyroidectomy [24-29]. Operative time and the amount of bleeding were not the risk factors [30]. However, in the study by Chew $\mathrm{C}$, they found incidental parathyroidectomy did not contribute to significant changes in postoperative serum calcium levels [31]. The injury of parathyroid gland may compromise their blood supply and lead to hypoparathyroidism $[32,33]$. Intraoperative parathyroid imaging can be used to mitigate surgical hypoparathyroidism in the intraoperative setting [34]. A metaanalysis showed low level of intraoperative PTH and presence of parathyroid gland in the pathological specimen were also risk factors of post-surgical hypoparathyroidism [35].

Another meta-analysis [36] also showed that perioperative PTH, preoperative vitamin D and postoperative changes in calcium were biochemical predictors for post-thyroidectomy hypocalcemia and clinical predictors included female, re-operation for bleeding, heavier thyroid specimens, parathyroid auto transplantation. Parathyroid autografts not only increased the rate of postoperative hypocalcemia but may increase the chance of permanent hypoparathyroidism [37]. However, some studies revealed parathyroid auto transplantation is a vital tool to avoid or minimize the risk for hypoparathyroidism following thyroidectomy $[38,39]$. The number of parathyroid glands remaining in situ was an important factor in prevention of permanent hypoparathyroidism [40]. A higher number of autos transplanted glands did not increase the chance of permanent hypoparathyroidism [39]. Thyroidectomy may cause hypocalcemia or hypoparathyroidism. Undiagnosed hypoparathyroidism can lead to multiple systemic sequelae such as chronic renal function impairment, reduced bone remolding, increased psychiatric complaints and basal ganglia calcification $[2,41]$. It is important to monitor parathyroid gland function after thyroidectomy.

Parathyroid hormone assay twenty minutes after thyroidectomy is an accurate way for predicting clinically relevant hypocalcemia [42]. In the study by Filho E they found that serum intact PTH levels measured with 4 hour or on the first morning after surgery are predictors of postoperative hypocalcemia $[43,44]$. Some studies indicated that intact PTH level on the first day after total thyroidectomy is a very useful predictor of permanent hypoparathyroidism due to its high negative predictive value. Serum intact PTH levels above $5 \mathrm{pg} / \mathrm{ml}$ virtually exclude presence of permanent hypoparathyroidism $[45,46]$. Indocyanine green (ICG) angiography can predict the vascularization of the parathyroid gland and obviate the need for postoperative measurement of calcium and PTH [47]. The oral calcium and vitamin D supplements play an important role in order to avoid postoperative hypocalcemia and increase the likelihood of a safe and early discharge from the hospital [48].Some factors associated with surgery [44] such as different anesthetic technique, site and procedure of surgery, duration of surgery, character of the patient can influence parathyroid function. A study reported that different anesthetic techniques can increase PTH levels from the reinduction to 3 minutes postinduction [49]. Some surgery of PTH excreting endocrine pancreatic neoplasm can decrease PTH and blood calcium levels [50,51]. Bariatric surgery may lead to the prevalence of secondary norm calcemic hyperparathyroidism, ranging from $17 \%$ - 70\% [52,53]. The primary hyperparathyroidism patients who had parathyroid hyperplasia and osteoporosis may have higher incidence of postoperative hypocalcemia after parathyroidectomy [54].

\section{Effect of RAI Treatment on Parathyroid Function for Benign Thyroid Disease}

RAI treatment can be used in benign thyroid diseases including Graves' disease, toxic multinodular goiter or toxic adenoma. The therapeutic dose of RAI for benign diseases is lower than that for DTC. Since 1975 [55], the cases of subsequent development of hyperparathyroidism after RAI treatment has been reported. Colaco [56] summarized that 40 cases of RAI treatment patients eventually developed hyperparathyroidism (including parathyroid adenoma and hyperplasia) without finding any malignant tumor. The mean age of the patients at the time of RAI treatment was 58.9 \pm 12.8 years and the mean latency period was $12.9 \pm 8.8$ years. The latent period was long. It could be the reason why a part of the 
study concluded that radioactive contact had no obvious effect on parathyroid function [57-59]. Table 1 summarized the literatures reported on patients who developed hyperparathyroidism after RAI treatment. We can find that the latest hyperparathyroidism occurred 30 years after RAI treatment, and most of them were female patients. Moreover, some studies showed that the latency period of benign lesions after radiation exposure was longer than that of malignant lesions [60-68].

Table 1: The literature reported on patients who developed hyperparathyroidism after RAI treatment.

\begin{tabular}{|c|c|c|c|c|c|c|c|}
\hline Author & Cases & Sex & Disease & Age (years) & Latency (years) & Dose & Parathyroid Disease \\
\hline Colaco, SM [56] & 8 & $1 \mathrm{M}$ & Nodular goiter & $38-54$ & Apr-35 & $\mathrm{N} / \mathrm{A}$ & Adenoma \\
\hline \multicolumn{3}{|c|}{$7 \mathrm{~F}$} & \multicolumn{5}{|c|}{ Graves' disease } \\
\hline Esselstyn [61] & 4 & $\mathrm{~F}$ & Graves' disease & 11-Aug & 28-Jun & $\mathrm{N} / \mathrm{A}$ & Adenoma/hyperplasia \\
\hline KawamuraJ [62] & 1 & M & Graves' disease & 24 & 12 & $12 \mathrm{mci}$ & Adenoma/hyperplasia \\
\hline Bondeso [63] & 7 & $\mathrm{~F}$ & Graves' disease & $34-73$ & 21-Mar & $\mathrm{N} / \mathrm{A}$ & Hyperplasia/adenoma \\
\hline Rosen [64] & 4 & M & Hyperthyroidism & $20-57$ & 30-Sep & $\mathrm{N} / \mathrm{A}$ & Adenoma/hyperplasia \\
\hline \multicolumn{8}{|c|}{ Nodular goiter } \\
\hline Cundiff [65] & 1 & $\mathrm{~F}$ & Hyperthyroidism & 67 & 6 & N/A & Adenmoa \\
\hline Acar [66] & 1 & M & Nodular goiter & 64 & 5 & N/A & Adenoma \\
\hline Netelenbos [67] & 2 & $\mathrm{~F}$ & Nodular goiter & $57-69$ & $20-\mathrm{Nov}$ & $\mathrm{N} / \mathrm{A}$ & Hyperparathyroidism \\
\hline Rasmuson [68] & 11 & M & Hyperthyroidism & $22-75$ & 19-Jan & $6-30 \mathrm{mCi}$ & Adenmoa \\
\hline
\end{tabular}

The specific mechanism of hyperparathyroidism after RAI treatment is still unclear, but the main risk factors may be related to age and treatment dose. Triggs and Williams [69] reported a high frequency of parathyroid adenomas in newborn rats after RAI treatment within 2 days of life. In addition, S Hanthi M [70] found that the older the patients were treated with RAI, the shorter the incubation time of developing hyperparathyroidism was. The parathyroid of older patients was more sensitive to RAI, which may be related to the instability of genes, thus leading to damage of apoptosis mechanism [71]. On the contrary, the younger the age of radiation exposure, the more likely it is to develop thyroid cancer earlier [72]. In the study by Piotr Szumowski [73], they treated benign thyroid diseases with absorbed dose of 140Gy, 180Gy and 240Gy according to different disease category, and found that PTH increased most significantly in patients with absorbed dose 240Gy within 6 months after RAI treatment. However, Hamilton TE [74] unmasked that the higher dose of exposure radiation may not increase the risk of hyperparathyroidism. Fjalling M studied 125 cases of hyperthyroidism patients adter RAI treatment with a average followed-up 20 years [75]. It was found that there was no increase in the incidence of hyperparathyroidism, which may be a bias caused by relatively small number of cases.

There are few studies reported on the short-term effects of the parathyroid gland function after RAI treatment. In the study by Piotr Szumowski [73], they investigated the PTH changes in patients (including 220 cases of toxic goiter nodules, 20 cases of non-toxicity nodular goiter and 80 cases of Graves' disease) treated with RAI. The result showed statistically significant increases in above-normal PTH serum levels in all patients. The highest rise in serum level of PTH occurred in toxic goiter nodules patients and the lowest in Graves' disease patients. Nevertheless, the blood calcium and blood phosphorus did not change significantly. The increase of PTH after radioactive iodine treatment may be caused by the inflammatory reaction caused by radiation. While blood calcium and phosphorus were maintained normal, which can be attributed to the mildly increased PTH whose action time was short and other regulatory mechanisms of calcium homeostasis could have been involved [76]. Ross DS [77], investigated PTH changes in 17 cases of hyperthyroidism patients after RAI treatment. The results showed that after therapy, patients quickly achieved hypothyroidism, whose PTH change was the most obvious (from $29 \pm 15$ to $75 \pm 29 \mathrm{ng} / \mathrm{ml}$ ). It is suggested that elevated PTH and blood calcium levels may be associated with iodine doses. More investigations are needed to elucidate the relationship between radiation dose and PTH or blood calcium change.

The treatment of benign thyroid diseases with RAI may cause increasing PTH with normal blood calcium in the early time, and development of adenoma and hyperplasia may occur in the long term. Three cases of hypoparathyroidism after RAI treatment has been reported [78-80]. There are case reports about patients appearing hypocalcemia after RAI treatment as well. Oksana Lazareva [81] reported 16-year-old young male patients with Graves' disease was given $15 \mathrm{mCi}$ RAI for treatment. After 11 weeks, he had paralysis, muscle spasms, fatigue and discomfort. Blood admission examination revealed reduced blood calcium and vitamin D, and highly increased PTH level. After in the process of oral calcium administration, blood calcium suddenly decreased. Eventually, it was considered as vitamin D deficiency and hungry bone syndrome (HBS)-a state of rapid calcium deposition into newly synthesized osteoid, resulting in rapid, profound, and prolonged hypocalcaemia 
associated with hypophosphataemia and hypomagnesaemia [82]. Similarly, Kateryna Komarovskiy [83] also reported 12-yearold female children displayed hypocalcemia symptom after RAI treatment. It is worth noting that this patient also had vitamin D reduction. The specific mechanism for hypoparathyroidism after RAI treatment is not clear yet. To sum up, RAI treatment may cause hyper or hypo-parathyroidism for benign thyroid diseases. Blood calcium and PTH should be regularly monitored after treatment for these patients.

\section{Effect of RAI Treatment on Parathyroid Function For DTC Patients}

DTC is a common endocrine malignancy; the yearly incidence of DTC has nearly tripled from 4.9 per 100000 in 1975 to 14.3 per in 2009. One study predicted that PTC will become the third most common cancer in women by 2019 [84,85]. It is suggested that radiation exposure is associated with the development of thyroid carcinoma, especially the thyroid radiated directly by the irradiation dose (more than 50 -100mGy). The smaller the contact's ageand the greater the risk of thyroid cancer was [72]. This could be one of the reasons of the rising incidence of thyroid cancer. Other factors may include increased sensitivity of ultrasound scan, iodine intake, and compounds with carcinogenic potential, such as a large class of xneobiotics (flame retardants, pesticides, repellents, or thermal insulators) [86]. Currently, thyroid surgery, RAI treatment and TSH inhibition therapy have become the standard treatment regimen for DTC patients. Total thyroidectomy combined with RAI treatment will improve the overall treatment efficiency and enable patients to have higher quality of life [87].

RAI treatment following thyroidectomy is suggested for many DTC patients. The purpose of RAI treatment is to remove residual thyroid and small metastatic lesions, to facilitate postoperative follow-up and recurrence monitoring. High-dose RAI therapy is associated with decreased risk of recurrence in high-risk papillary thyroid cancer [88]. It is now accepted that the RAI treatment is very safe and the advantages of treating DTC with RAI outweigh the disadvantages [89]. Treatment with RAI can produce early and late complications. The common early complications include swelling and discomfort in the neck, xerostomia, dry eye, abnormalities of taste and smell, dysphagia, nausea, vomiting, bone marrow suppression [90], gonadal damage (hypospermia or temporary amenorrhea/oligomenorrhea), nasal dryness and obstruction, and nasolacrimal obstruction [91-96]. The late complications include permanent salivary gland dysfunction, leukemia and secondary malignancy, pulmonary fibrosis, fertility problems [97-102].

The parathyroid gland is an adjacent organ of the thyroid. Theoretically, RAI may influence parathyroid function. In the study by Aytekin Guven [103], 19 DTC patients after RAI therapy (therapeutic dose 100 - 150mCi) were measured PTH, blood calcium, phosphorus at the first, third, sixth, twelfth month. PTH gradually decreased between the first and sixth month, but in the normal range, and restored baseline at twelfth month. Blood calcium level was similar to this trend without significant difference. Some patients appeared hypocalcemia without any clinical symptoms. Zhi-hua Zhao et al. [104] found there were still hypoparathyroidism happened after RAI treatment and the changes of PTH and blood calcium before and after the RAI treatment were not statistically significant. Generally, PTH reduced after RAI treatment for DTC, and a small number of patients could appear hypocalcemia. The underlying mechanism of diminished parathyroid function after RAI by a non-targeted effect of ionizing radiation called a "bystander effect" on the adjacent cells (RIBE) [103,105]. Gene expression changes may lead to RIBE occurrence [106]. There was one case reported that a patient developed hyperparathyroidism after RAI treatment for DTC. A 17-year-old male patient with thyroid papillary carcinoma underwent 2 times RAI treatment (total doses $263 \mathrm{mCi}$ ). Two years after RAI treatment, a parathyroid adenoma was detected by a neck ultrasound examination.

The specific risk factors that influence on the parathyroid gland function after RAI treatment for DTC are still needed to be further studied. Glazebrook G [107] found that age, sex, thyroid gland excision scope, operation method, iodine doses, neck radiation exposure, relative location between thyroid and parathyroid were not relevant risk factors of low parathyroid gland function. Aytekin Guven [103] found that age, gender, iodine dose had no impact on the PTH changes both before and after RAI therapy. Currently, the effect of RAI treatment on parathyroid gland function is not very clear yet. The studies mainly focused on the changes of PTH, blood calcium and blood phosphorus at different stages before and after the treatment of RAI. The sample sizes in these studies were small and the intervals of PTH and blood calcium measurement were different among different studies. No systematic study was published focusing on long-term (over one year) changes of PTH.

\section{Conclusion}

To sum up, thyroidectomy and RAI treatment may influence the parathyroid function in GD, TMNG, TA and DTC patients. Thyroidectomy may cause hypoparathyroidism and hypocalcaemia in benign and DTC patients. For benign thyroid disease, RAI treatment may cause increasing PTH in the short term and may induce parathyroid adenoma or hyperplasia in the long term. For DTC patients, parathyroid gland function may transiently decline after RAI treatment. It is important to monitor PTH and blood calcium regularly in order to detect early abnormal parathyroid function for those patients.

\section{Acknowledgement}

None.

\section{Conflict of Interest}

No conflict of interest. 


\section{References}

1. Shoback DM, Bilezikian JP, Costa AG, Dempster D, Dralle H, et al. (2016) Presentation of Hypoparathyroidism: Etiologies and Clinical Features. J Clin Endocrinol Metab 101: 2300-2312.

2. Hicks G, George R, Sywak M (2017) Short and long-term impact of parathyroid autotransplantation on parathyroid function after total thyroidectomy. Gland Surg 6(Supp 1): S75-S85.

3. Reid L, Muthukrishnan B, Patel D, Mike S Crane, Murat Akyol, et al. (2018) Presentation, diagnostic assessment and surgical outcomes in primary hyperparathyroidism: a single centre's experience. Endocr Connect 7(10): 1105-1115

4. Al Thani H, El Matbouly M, Al Sulaiti M, Asim M, Majzoub A, et al. (2018) Management and outcomes of hyperparathyroidism: a case series from a single institution over two decades. Ther Clin Risk Manag 14: 1337-1345.

5. Ugalde I, Bello SM, Oneto S, Ciment A (2018) The forgotten electrolyte when hypercalcaemia manifest as gait instability and altered mental status. BMJ Case Rep.

6. Pattanayak P, Santhanam P, Javadi MS, Solnes LB, Rowe SP (2017) Unilateral Submandibular Gland Atrophy and Sialolithiasis Diagnosed on 99mTc-MIBI SPECT/CT in a Patient With Primary Hyperparathyroidism. Clin Nucl Med 42 (12): 939-940.

7. Belem LC, Souza CA, Souza AJ, Dante Luiz Escuissato, Bruno Hochhegger et al. (2017) Metastatic pulmonary calcification: high-resolution computed tomography findingsin 23 cases. Radiol Bras 50(4): 231-236.

8. Hanna RM, Kaldas M, Arman F, Wang M, Hammer T, et al. (2018) Hypercalcemia-induced acute kidney injury in a Caucasian female due to radiographically silent systemic sarcoidosis. Clin Nephrol Case Stud 6: 21-26.

9. Lee Y, Goyal K, Prasad B (2018) Acute Kidney Injury in a 31-year-old Male as a Consequence of Multiple Myeloma. Cureus10(6): e2881.

10. Sunkara T, Caughey ME, Rawla P, Yarlagadda KS, Gaduputi V (2018) Severe Acute Pancreatitis as an Index Clinical Manifestation of Parathyroid Adenoma. Cureus 10(4): e2445.

11. Otsuka Y, Kamata K, Minaga K, Takenaka M, Watanabe T, et al. (2018) Acute Pancreatitis with Disturbed Consciousness Caused by Hyperparathyroidism. Intern Med 57(21): 3075-3078.

12. Richa CG, Saad KJ, Chaaban AK, Mohamad Souheil El Rawas (2018) A rare case of hypercalcemia-induced pancreatitis in a first trimester pregnant woman. Endocrinol Diabetes Metab Case Rep.

13. Gebreselassie A, Mehari A, Dagne R, Berhane F, Kibreab A (2018) Hypercalcemic pancreatitis a rare presentation of sarcoidosis: A case report. Medicine (Baltimore) 97(2): e9580.

14. Kawakita C, Kinomura M, Gon Y, Chika Okita, Katsuyoshi Katayama, et al (2018) A case of fatal osteolytic hypercalcemia complicated with IgG4related ophthalmic disease leading to renal failure. CEN Case Rep 8(1): 20-30.

15. Marinheiro R, Parreira L, Amador P, Francisco Sardinha, Sara Gonçalves, et al. (2018) Primary Ventricular Fibrillation in a Patient with Mild Hypercalcemia. Arq Bras Cardiol 110(4): 393-396.

16. Toniato A, Boschin IM, Piotto A Pelizzo M, Sartori P (2008) Thyroidectomy and parathyroid hormone: tracing hypocalcemia-prone patients. Am J Surg 196(2): 285-288.

17. Zambudio AR, Rodriguez J, Riquelme J, Soria T, Canteras $\mathrm{M}$, et al (2004) Prospective study of postoperative complications after total thyroidectomy for multinodular goiters by surgeons with experience in endocrine surgery. Ann Surg 240(1): 18-25.

18. Puzziello A, Rosato L, Innaro N, Orlando G, Avenia N, et al. (2014) Hypocalcemia following thyroid surgery: incidence and risk factors. A longitudinal multicenter study comprising 2,631 patients. Endocrine 47(2): 537-542.
19. Almquist M, Ivarsson K, Nordenstrom E, Bergenfelz A (2018) Mortality in patients with permanent hypoparathyroidism after total thyroidectomy. Br J Surg 105(10): 1313-1318.

20. Hallgrimsson P, Nordenstrom E, Bergenfelz A, Almquist M (2012) Hypocalcaemia after total thyroidectomy for Graves' disease and for benign atoxic multinodular goitre. Langenbecks Arch Surg 397(7): 1133-1137.

21. Kalyoncu D, Gonullu D, Gedik ML, Muzaffer Er, Erol Kuroğlu, et al. (2013) Analysis of the factors that have an effect on hypocalcemia following thyroidectomy. Ulus Cerrahi Derg 29 (4): 171-176.

22. Davis JR, Dackiw AP, Holt SA, Nwariaku FE, Oltmann SC (2018) Rapid Relief: Thyroidectomy is a Quicker Cure than Radioactive Iodine Ablation (RAI) in Patients with Hyperthyroidism. World j surg 43(3):812-817.

23. Hallgrimsson P, Nordenstrom E, Almquist M, Bergenfelz AO (2012) Risk factors for medically treated hypocalcemia after surgery for Graves' disease: a Swedish multicenter study of 1,157 patients. World J Surg 36(8): 1933-1942.

24. Bai B, Chen Z, Chen W (2018) Risk factors and outcomes of incidental parathyroidectomy in thyroidectomy: A systematic review and metaanalysis. Plos One 13(11): e207088.

25. Vasileiadis I, Charitoudis G, Vasileiadis D, Kykalos S, Karatzas T (2018) Clinicopathological characteristics of incidental parathyroidectomy after total thyroidectomy: The effect on hypocalcemia. A retrospective cohort study. Int J Surg 55: 167-174.

26. Orloff LA, Wiseman SM, Bernet VJ, Fahey TJ, Shaha AR, et al. (2018) American Thyroid Association Statement on Postoperative Hypoparathyroidism: Diagnosis, Prevention, and Management in Adults. Thyroid 28(7): 830-841.

27. Papaj P, Koziel S, Mrowiec S (2017) Analysis of factors affecting the development of hypocalcaemia after multinodular goitre surgery. Pol Przegl Chir 89(2): 26-30.

28. Christakis I, Zacharopoulou P, Galanopoulos G, Ilias Demetrios Kafetzis, Spiros Dimas, et al. (2017) Inadvertent parathyroidectomy risk factors in 1,373 thyroidectomies-male gender and presence of lymphadenopathy, but not size of gland, independently increase the risk. Gland Surg 6(6): 666-674.

29. Wang YH, Bhandari A, Yang F, Wei Zhang, Li jun Xue, et al. (2017) Risk factors for hypocalcemia and hypoparathyroidism following thyroidectomy: a retrospective Chinese population study. Cancer Manag Res 9: 627-635.

30. Ozogul B, Akcay MN, Akcay G, Ozgur Hakan Bulut (2014) Factors affecting hypocalcaemia following total thyroidectomy: a prospective study. Eurasian J Med 46(1): 15-21.

31. Chew C, Li R, Ng MK, Fleming B (2018) Incidental parathyroidectomy during total thyroidectomy is not a direct cause ofpost-operative hypocalcaemia. Anz J Surg 88(3): 158-161.

32. Stevenson A, Mihai R (2018) Patients' views about parathyroid transplantation for post-thyroidectomy hypoparathyroidism. Langenbecks Arch Surg 403(5): 623-629.

33. Sitges Serra A, Gallego Otaegui L, Suarez S, Lorente Poch L, Munné A et al. (2017) Inadvertent parathyroidectomy during total thyroidectomy and central neck dissection for papillary thyroid carcinoma. Surgery 161(3): 712-719.

34. Kazaure HS, Sosa JA (2018) Surgical Hypoparathyroidism. Endocrinol Metab Clin North Am 47(4): 783-796.

35. Kakava K, Tournis S, Papadakis G, Karelas I, Stampouloglou P, et al. (2016) Postsurgical Hypoparathyroidism: A Systematic Review. In Vivo 30(3): 171-179.

36. Edafe O, Antakia R, Laskar N, Uttley L, Balasubramanian SP (2014) Systematic review and meta-analysis of predictors of post-thyroidectomy hypocalcaemia. Br J Surg 101(4): 307-320. 
37. Sitges Serra A, Lorente Poch L, Sancho J (2018) Parathyroid auto transplantation in thyroid surgery. Langenbecks Arch Surg 403(3): 309315.

38. Iorio O, Petrozza V, De Gori A, Bononi M, Porta N, et al. (2019) Parathyroid Auto transplantation During thyroid Surgery. Where we are? A Systematic Review on Indications and Results. J Invest Surg 32(7): 594-601.

39. Su A, Gong Y, Wu W, Li Z, Zhu J (2018) Does the number of parathyroid glands auto transplanted affect the incidence of hypoparathyroidism and recovery of parathyroid function? Surgery.

40. Lorente Poch L, Sancho JJ, Ruiz S, Sitges Serra A (2015) Importance of in situ preservation of parathyroid glands during total thyroidectomy. $\mathrm{Br}$ Surg 102(4): 359-367.

41. Mitchell DM, Regan S, Cooley MR, Lauter KB, Vrla MC, et al. (2012) Longterm follow-up of patients with hypoparathyroidism. J Clin Endocrinol Metab 97(12): 4507-4514.

42. Reddy AC, Chand G, Sabaretnam M, Mishra A, Agarwal G, et al. (2016) Prospective evaluation of intra-operative quick parathyroid hormone assay as an early predictor of post thyroidectomy hypocalcaemia. Int J Surg 34: 103-108.

43. Filho E, Machry RV, Mesquita R, Scheffel RS, Maia AL, et al. (2018) The timing of parathyroid hormone measurement defines the cut-off values to accurately predict postoperative hypocalcemia: a prospective study Endocrine 61(2): 224-231.

44. Mazotas IG, Wang TS (2017) The role and timing of parathyroid hormone determination after total thyroidectomy. Gland Surg 6(1): S38-S48.

45. Calvo EP, Rivera BJ, Artes CM, Serrano González J, García Pavía A, et al. (2018) Serum levels of intact parathyroid hormone on the first day after total thyroidectomy as predictor of permanent hypoparathyroidism. Endocrinol Diabetes Nutr 66(3): 195-201.

46. Marcinkowska M, Sniecikowska B, Zygmunt A, Brzezinski J, Dedecjus M, et al. (2017) Postoperative hypoparathyroidism in patients after total thyroidectomy - retrospective analysis. Neuro Endocrinol Lett 38(7): 488-494.

47. Vidal FJ, Sadowski SM, Belfontali V, Guigard S, Poncet A, et al (2018) Randomized clinical trial of intraoperative parathyroid gland angiography with indocyanine green fluorescence predicting parathyroid function after thyroid surgery. Br J Surg 105(4): 350-357.

48. Docimo G, Tolone S, Ruggiero R, Gubitosi A, Pasquali D, et al. (2013) Total thyroidectomy without prophylactic central neck dissection combined with routine oral calcium and vitamin D supplements: is it a good option to achieve alow recurrence rate avoiding hypocalcemia? A retrospective study. Minerva Chir 68(3): 321-328.

49. Hong JC, Morris LF, Park EJ, Ituarte PH, Lee CH, et al. (2011) Transient increases in intraoperative parathyroid levels related to anesthetic technique. Surgery 150(6): 1069-1075.

50. Matsen SL, Yeo CJ, Hruban RH, Ralph H Hruban, Michael A Choti (2005) Hypercalcemia and pancreatic endocrine neoplasia with elevated PTHrP: report oftwo new cases and subject review. J Gastro Intest Surg 9(2): 270-279.

51. Albu A, Zirnea A, Georgescu O, Terzea D, Jinga D, et al. (2008) Malignant insulinoma with hepatic and pulmonary metastases associated with primary hyperparathyroidism. Case report and review of the literature. J Med Life 1(2): 210-217

52. Casella C, Molfino S, Mittempergher F, Carlo Cappelli, Nazario Portolani (2018) Predictive Factors of Secondary Normocalcemic Hyperparathyroidism after Roux-en-Y Gastric Bypass. Int J Endocrinol pp. 5010287.

53. Wei JH, Lee WJ, Chong K, Lee YC, Chen SC, et al. (2018) High Incidence of Secondary Hyperparathyroidism in Bariatric Patients: Comparing Different Procedures. Obes Surg 28(3): 798-804.

54. Kaya C, Tam AA, Dirikoc A, Kılıçyazgan A, Kılıç M, et al. (2016) Hypocalcemia development in patients operated for primary hyperparathyroidism: Can it be predicted preoperatively? Arch Endocrinol Metab 60(5): 465-471.

55. Rosen IB, Strawbridge HG, Bain J (1075) A case of hyperparathyroidism associated with radiation to the head and neck area. Cancer-Am Cancer Soc 36(3): 1111-1114.

56. Colaco SM, Si M, Reiff E (2007) Hyperparathyroidism after radioactive iodine therapy. Am J Surg 194(3): 323-327.

57. Holten I, Christiansen C (1984) Unchanged parathyroid function following irradiation for malignancies of the head and neck. Cancer-Am Cancer Soc53(4): 874-877.

58. Talmi YP, Wolf GT, Esclamado R, Carroll WR, Sassler AM (1993) Ionized serum calcium levels following combined treatment for cancer of the headand neck. Laryngoscope 103(9): 1048-1051.

59. Mortensen LS, Smidt K, Jorgensen A, Nielsen JT, Laurberg P, et al. (2005) Long-term parathyroid- and c-cell function after radioiodine for benign thyroid diseases. Basic Clin Pharmacol Toxicol 97(1): 22-28.

60. Kikuchi S, Perrier ND, Ituarte P, Siperstein AE, Duh QY, et al. (2004) Latency period of thyroid neoplasia after radiation exposure. Ann Surg 239(4): 536-543.

61. Esselstyn CJ, Schumacher OP, Eversman J, Sheeler L, Levy WJ (1982) Hyperparathyroidism after radioactive iodine therapy for Graves' disease. Surgery 92(5): 811-813.

62. Kawamura J, Tobisu K, Sanada S, Okada Y, Yoshida O, et al. (1983) [Hyperparathyroidism after radioactive iodine therapy for Graves' disease: a case report]. Hinyokika Kiyo 29(11): 1513-1519.

63. Bondeson AG, Bondeson L, Thompson NW (1989) Hyperparathyroidism after treatment with radioactive iodine: not only a coincidence? Surgery 106(6): 1025-1027

64. Rosen IB, Palmer JA, Rowen J, Luk SC (1984) Induction of hyperparathyroidism by radioactive iodine. Am J Surg 148(4): 441-445.

65. Cundiff JG, Portugal L, Sarne DH (2001) Parathyroid adenoma after radioactive iodine therapy for multinodular goiter. Am J Otolaryngol 22(5): 374-375.

66. Acar T, Gomceli I, Aydin R (2003) Primary hyperparathyroidism due to giant adenoma after treatment with radioactive iodine. N Z Med J 116(1174): U441.

67. Netelenbos JC, Lips P (1981) Hyperparathyroidism after radioactive iodine therapy. Arch Intern Med 141(11): 1555-1556.

68. Rasmuson T, Tavelin B (2006) Risk of parathyroid adenomas in patients with thyrotoxicosis exposed to radioactive iodine. Acta Oncol 45(8): 1059-1061.

69. Triggs SM, Williams ED (1977) Irradiation of the thyroid as a cause of parathyroid adenoma. Lancet 1(8011): 593-594.

70. Colaco SM, Si M, Reiff E (2007) Hyperparathyroidism after radioactive iodine therapy. AM J SURG 194(3): 323-327.

71. Suzuki K, Ojima M, Kodama S, Watanabe M (2006) Delayed activation of DNA damage checkpoint and radiation-induced genomic instability. Mutat Res 597(1-2): 73-77.

72. Iglesias ML, Schmidt A, Ghuzlan AA, Lacroix L, Vathaire F, et al. (2017) Radiation exposure and thyroid cancer: a review. Arch Endocrinol Metab 61(2):180-187

73. Szumowski P, Abdelrazek S, Mojsak M, Rogowski F, Kociura Sawicka A, et al. (2013) Parathyroid gland function after radioiodine ((131)I) therapy for toxic and non-toxic goitre. Endokrynol Pol 64(5): 340-345.

74. Hamilton TE, Davis S, Onstad L, Kopecky KJ (2005) Hyperparathyroidism in persons exposed to iodine-131 from the Hanford Nuclear Site. J Clin Endocrinol Metab 90(12): 6545-6548.

75. Fjalling M, Dackenberg A, Hedman I, Tisell LE (1983) An evaluation of the risk of developing hyperparathyroidism after 131I treatmentfor thyrotoxicosis. Acta Chir Scand 149(7): 681-686. 
76. Lowe H, Mc Mahon DJ, Rubin MR, Bilezikian JP, Silverberg SJ (2007) Normocalcemic primary hyperparathyroidism: further characterization of a new clinical phenotype. J Clin Endocrinol Metab 92(8): 3001-3005.

77. Ross DS, Nussbaum SR (1989) Reciprocal changes in parathyroid hormone and thyroid function after radioiodinetreatment of hyperthyroidism. J Clin Endocrinol Metab 68(6): 1216-1219.

78. Eipe J, Johnson SA, Kiamko RT (1968) Hypoparathyroidism following 131-I therapy for hyperthyroidism. Arch Intern Med 121(3): 270-272.

79. Better OS, Garty J, Brautbar N (1969) Diminished functional parathyroid reserve following I-131 treatment for hyperthyroidism. Isr J Med Sci 5: 419-422.

80. Harden RM, Harrison MT, Alexander WD (1963) Phosphate excretion and parathyroid function after radioiodine therapy and thyroidectomy. Clin sci 25: 27-36.

81. Lazareva O, Panayiotopoulos A, Kazachkova I, Jacobson Dickman E (2014) A teenage boy with hypocalcemia after radioablation for Graves' disease. J Pediatr Endocrinol Metab 27(3-4): 379-382.

82. Witteveen JE, Van Thiel S, Romijn JA, Hamdy NA (2013) Hungry bone syndrome: still a challenge in the post-operative management of primary hyperparathyroidism: a systematic review of the literature. Eur J Endocrinol 168(3): R45-R53.

83. Komarovskiy K, Raghavan S (2012) Hypocalcemia following treatment with radioiodine in a child with Graves' disease. Thyroid 22(2): 218-222.

84. Haugen BR, Alexander EK, Bible KC, Doherty GM, Mandel SJ, et al. (2016)2015 American Thyroid Association Management Guidelines for Adult Patients with Thyroid Nodules and Differentiated Thyroid Cancer: The American Thyroid Association Guidelines Task Force on Thyroid Nodules and Differentiated Thyroid Cancer. Thyroid 26(1): 1-133.

85. Aschebrook Kilfoy B, Schechter RB, Shih YC, Kaplan EL, Chiu BC, et al (2013) The clinical and economic burden of a sustained increase in thyroid cancer incidence. Cancer Epidemiol Biomarkers Prev 22(7): 1252-1259.

86. Marcello MA, Malandrino P, Almeida JF, Martins MB, Cunha LL, et al (2014) The influence of the environment on the development of thyroid tumors: a new appraisal. Endocr Relat Cancer 21(5): T235-T254.

87. Yin X, Li Z, Zhang Z, Wang X (2018) Clinical effect of total thyroidectomy combined with radioactive iodine in thyroid cancer treatment. Pak J Pharm Sci 31(4): 1675-1678.

88. Gray KD, Bannani S, Caillard C, Amanat S, Ullmann TM, et al. (2018) High-dose radioactive iodine therapy is associated with decreased risk of recurrence in high-risk papillary thyroid cancer. Surgery 165(1): 3743.

89. Tulchinsky M, Binse I, Campenni A, Dizdarevic S, Giovanella L, et al (2018) Radioactive Iodine Therapy for Differentiated Thyroid Cancer: Lessons from Confronting Controversial Literature on Risks for Secondary Malignancy. J Nucl Med 59(5):723-725.

90. Probst S, Abikhzer G, Chausse G, Tamilia M (2018) I-131 RadiationInduced Myelosuppression in Differentiated Thyroid Cancer Therapy. Mol Imaging Radionucl Ther 27(2): 84-87.

91. Fard Esfahani A, Emami Ardekani A, Fallahi B, Fard Esfahani P, Beiki D, et al. (2014) Adverse effects of radioactive iodine-131 treatment for differentiated thyroid carcinoma. Nucl Med Commun 35(8): 808-817.
92. Savage MW, Sobel RK, Hoffman HT, Carter KD, Finkelstein MW, et al. (2015) Salivary gland dysfunction and nasolacrimal duct obstruction: stenotic changes following I-131 therapy. Ophthalmic Plast Reconstr Surg 31(3): e50-e52.

93. Lu L, Shan F, Li W (2016) Short-Term Side Effects after Radioiodine Treatment in Patients with Differentiated Thyroid Cancer. Biomed Res Int 2016: 4376720 .

94. Pashnehsaz M, Takavar A, Izadyar S, Seyed Salman Zakariaee, Mahmoud Mahmoudi, et al. (2016) Gastrointestinal Side Effects of the Radioiodine Therapy for the Patients with Differentiated Thyroid Carcinoma Two Days after Prescription. World J Nucl Med 15(3): 173-178.

95. Server EA, Kirgezen T, Celebi OO, Yildiz M, Yigit O, et al. (2017) How does radioactive iodine affect the nose? Laryngoscope 127(12): 2698-2702.

96. Suat B, Deniz TE, Ozgur Y, Muhammet Y, Tevfik Fikret C (2016) The effects of radioactive iodine therapy on olfactory function. AM J Rhinol Allergy 30(6): 206-210.

97. Walgraeve D, Verhoef G, Stul M, Jean Jacques Cassimana B, Cristina Mecucci, et al. (1991) Chronic myelogenous leukemia after treatment with 131I for thyroid carcinoma. Report of a case and review of the literature. Cancer Genet Cytogenet 55(2): 217-224.

98. Shimon I, Kneller A, Olchovsky D (1995) Chronic myeloid leukaemia following 131I treatment for thyroid carcinoma: a report of two cases and review of the literature. Clin Endocrinol (Oxf) 43(5): 651-654.

99. Laurenti L, Salutari P, Sica S, Piccirillo N, Zini G, et al. (1998) Acute myeloid leukemia after iodine-131 treatment for thyroid disorders. Ann Hematol 76(6): 271-272.

100. Pacini F, Schlumberger M, Dralle H, Smit JW, Wiersinga W, et al. (2006) European consensus for the management of patients with differentiated thyroid carcinoma of the follicular epithelium. Eur J Endocrinol 154(6): 787-803.

101. Buyuksimsek M, Paydas S, Ogul A, Emine Bağır, Melek Ergin, et al. (2018) Myeloid Neoplasia and Lymphoblastic Lymphoma with Eosinophilia After Radioactivelodine: A Case Report. Balkan Med J 35(2): 199-202.

102. Albano D, Bertagna F, Panarotto MB, Panarotto MB, Giubbini R (2017) Early and late adverse effects of radioiodine for pediatric differentiated thyroid cancer 64(11).

103. Guven A, Salman S, Boztepe H, Yarman S, Tanakol R, et al. (2009) Parathyroid changes after high dose radioactive iodine in patients with thyroid cancer. Ann Nucl Med 23(5): 437-441.

104. Zhao ZH, Li FQ, Han JK, Xian Jun Li (2015) Effect of (131) I 'clear residual thyroid tissue' after surgery on the function of parathyroid gland in differentiated thyroid cancer. Exp Ther Med 10(6): 2079-2082.

105. Tzanela M, Thalassinos NC, Nikou A, Georgiadis G, Philokiprou D (1993) Effect of 131I treatment on the calcitonin response to calcium infusion in hyperthyroid patients. Clin Endocrinol (Oxf) 38(1): 25-28.

106. Sokolov M, Neumann R (2018) Changes in gene expression as one of the key mechanisms involved in radiation-induced bystander effect. Biomed Rep 9: 99-111.

107. Glazebrook GA (1987) Effect of decicurie doses of radioactive iodine 131 on parathyroid function. Am J Surg 154(4): 368-373. 


\section{ISSN: 2574-1241}

DOI: 10.26717/BJSTR.2019.22.003780

Lin Li. Biomed J Sci \& Tech Res

CC (9) This work is licensed under Creative

Submission Link: https://biomedres.us/submit-manuscript.php

$\begin{array}{ll}\text { BIOMEDICAL } & \text { Assets of Publishing with us } \\ \text { RESEARCHES } & \text { Global archiving of articles } \\ \text { - Immediate, unrestricted online access }\end{array}$

